\title{
Rancang Bangun Simdalev Berbasis Framework CodeIgniter-Harviacode untuk Manajemen Pengendalian dan Evaluasi Pembangunan Daerah Kabupaten Tana Tidung
}

\author{
Arif Fadllullah', Rudy ${ }^{2}$, Sultan Mahdi ${ }^{3}$ \\ ${ }^{1,2}$ Teknik Elektro, Fakultas Teknik, Universitas Borneo Tarakan \\ 1e-mail: arif.fadl@borneo.ac.id \\ 2e-mail: rudy20@gmail.com

\begin{tabular}{ccc}
\hline Diterima & Direvisi & Disetujui \\
$04-09-2020$ & $04-11-2020$ & $10-01-2020$ \\
\hline
\end{tabular}

\begin{abstract}
Abstrak - Salah satu wujud nyata Pemerintah Kabupaten Tana Tidung dalam mengelola program kerjanya secara transparan dan akuntabel adalah melalui proses monitoring dan evaluasi (monev) secara komprehensif dan berkala. Hanya saja selama ini proses monev masih dilakukan secara manual dengan beberapa kelemahan, seperti format laporan yang tidak seragam, keterlambatan proses penyampaian laporan untuk SKPD yang jauh, terjadinya kesalahan input dalam laporan karena data tercecer, dan tidak adanya kontrol monitoring progress realisasi anggaran per triwulan secara efektif dan efisien. Oleh karena itu, penelitian ini mengusulkan untuk mengembangkan Simdalev (Sistem Informasi Manajemen Pengendalian dan Evaluasi Pembangunan Daerah) Kabupaten Tana Tidung. Simdalev ini dibangun dalam bahasa pemrograman web PHP diatas framework CodeIgniter dan generator CRUD Harviacode. Pengembangan dalam pembuatan aplikasi ini menggunakan metode Waterfall atau biasa disebut SDLC (Software Development Life Cycle) dan diuji terhadap 33 responden dengan pengujian black-box, kompabilitas, dan usabilitas. Hasil penelitian menunjukkan bahwa pengujian black-box sebagian besar bernilai valid, pengujian kompatibilitas bernilai kompabilitas untuk semua jenis browser, serta pengujian usabilitas bernilai 80,79 yang menunjukkan antarmuka Simdalev dapat digunakan oleh pengguna dengan mudah.
\end{abstract}

Kata Kunci: CodeIgniter-Harviacode, Kabupaten Tana Tidung, Waterfall

\begin{abstract}
One of the concrete actions of Tana Tidung 's Government in managing its work program transparently and accountably, is through the monitoring and evaluation (monev) process comprehensive and periodically. But this monev process is still done manually with several weaknesses, such as non-uniform report formats, delays in the process of submitting reports for distant SKPD, input errors in the report due to scattered data, and there is no supervision of the quarterly budget realization by effective and efficient. Therefore, this study proposes to develop Simdalev of Tana Tidung City. Simdalev was built in the PHP programming language above the CodeIgniter framework and the Harviacode CRUD generator. The development method that making this application uses the Waterfall method or commonly called SDLC (Software Development Life Cycle) and tested on 33 respondents with black-box, compatibility, and reusability testing. The results show that the black-box test was valid, compatibility testing was compatible for all types of browsers, and the usability test was 80.79 which shows the Simdalev interface can be used by users easily.
\end{abstract}

Keywords: CodeIgniter-Harviacode, Tana Tidung City, Waterfall

\section{PENDAHULUAN}

Berdasarkan Undang-Undang Republik Indonesia Nomor 34 Tahun 2007, Kabupaten Tana Tidung merupakan kabupaten yang resmi terbentuk sebagai hasil pemekaran dari Kabupaten Bulungan yang disahkan oleh Presiden RI pada tanggal 10 Juli 2007 dengan ibukota berkedudukan di Tideng Pale, Kecamatan Sesayap. Kabupaten ini menjadi kabupaten kesepuluh atau daerah otonom keempatbelas di Provinsi Kalimantan Timur. Namun, setelah lahirnya Undang-Undang Nomor 20 Tahun
2012 pada tanggal 25 Oktober 2012 tentang pembentukan Daerah Otonom Baru Provinsi Kaltara (Kalimantan Utara) yang merupakan pemekaran dari Provinsi Kalimantan Timur, maka Kabupaten Tana Tidung menjadi salah satu kabupaten pada wilayah pemekaran di Provinsi Kaltara (Humas KTT, 2016).

Sebagai kabupaten termuda di wilayah Kaltara yang memiliki sumberdaya alam yang melimpah, sebagai jalur perekonomian yang strategis, serta berada pada jalur poros tengah wilayah utara Indonesia yang menghubungkan Kota Tarakan, Kabupaten Bulungan, 
Kabupaten Nunukan, dan Kabupaten Malinau. Maka menjadikan Kabupaten Tana Tidung (biasa disingkat KTT) harus mampu mengejar ketertinggalan pembangunan segala aspek dari 4 kabupaten/kota lainnya di Provinsi Kaltara yang telah lama berdiri. Untuk mempu mengejar ketertinggalan itu, maka perlu adanya tatakelola pemerintahan yang baik (good governance) guna mengembangkan potensi wilayah yang telah dirumuskan dalam RPJMD (Rencana Pembangunan Jangka Menengah Daerah) dan RKPD (Rencana Kerja Pemerintahan Daerah) KTT, meliputi pengembangan sistem pusat pelayanan, perwilayahan pembangunan, pusat pemukiman pedesaan dan perkotaan, prasarana wilayah, serta kawasan strategis (Tim Penyusun Evaluasi RKPD, 2019).

Saat ini, tata kelola pemerintahan yang baik (good governance) dalam pembangunan berkelanjutan sudah menjadi tuntutan untuk dilaksanakan oleh semua Provinsi dan Kabupaten/Kota di seluruh Indonesia, tanpa terkecuali KTT. Menurut Mardiasmo (2018), terdapat empat pilar yang menjadi keharusan dan saling berkaitan untuk mewujudkan good governance yaitu: 1) transparansi yang diartikan sebagai keterbukaan pemerintah dalam memberikan informasi terkait alokasi anggaran yang dapat dimonitor oleh berbagai pihak. 2) Partisipasi atau keterlibatan SKPD dan masyarakat dalam menyusun RPJMD dan RKPD melalui musrembang secara terbuka dan konstruktif. 3) Akuntabilitas sebagai bentuk kewajiban mengevaluasi dan mempertanggungjawabkan keberhasilan atau kegagalan pelaksanaan misi pemerintahan KTT dalam mencapai tujuan dan sasaran yang telah ditetapkan. 4) Value for money yang meminimalkan input dan memaksimalkan output, rasio antara input dan output, dan keberhasilan pemerintahan KTT (tujuan tercapai dan program/kegiatan telah dilakukan dengan benar).

Salah satu wujud nyata Pemerintah KTT dalam mengelola program kerjanya secara cepat, tepat, transparan dan akuntabel, serta tingkat ketelitian yang tinggi agar sesuai dengan prinsip empat pilar good governance adalah melalui proses monitoring dan evaluasi (monev) secara komprehensif dan berkala. Proses monitoring ini mencakup mulai dari proses pengumpulan data realisasi program/kegiatan, pelaporan kegiatan, hingga penilaian dan evaluasi capaian kinerja. Ini dilakukan agar dapat diketahui status kemajuan penggunaan anggaran, membuktikan dan mempertanggungjawabkan kepada masyarakat atas penggunaan anggaran yang dikelola apakah telah sesuai dengan peruntukannya (prinsip akuntabilitas), serta untuk menginventarisir faktor-faktor pendukung dan penghambat sebagai bahan evaluasi agar program/kegiatan selanjutnya dapat lebih berdayaguna dan berhasil-guna (prinsip efektivitas dan efisiensi) (Maghfiroh, 2017).
Beberapa aktivitas monev dalam RKPD yang hingga saat ini juga telah dilaksanakan oleh Pemerintah KTT, diantaranya: 1) Mengetahui kegiatan yang sudah dilaksanakan tahun lalu. Beberapa kegiatan yang sudah selesai dilaksanakan tahun lalu masih perlu dipantau untuk mengetahui kondisi terkini sekaligus tingkat kebermanfaatannya terhadap masyarakat. 2) Mengetahui progress/posisi realisasi kegiatan sekarang terhadap target akhir tahun anggaran. 3) Memantau hasil pelaksanaan pembangunan fisik yang dikerjakan oleh penyedia/pihak ketiga (Monev Untuk Perencanaan yang Lebih Baik, 2019).

Hanya saja selama ini aktivitas dalam penyusunan laporan hasil monev RKPD di Pemerintahan KTT masih memiliki kendala, diantaranya: 1) belum adanya laporan yang memiliki format yang seragam, sehingga seringkali bentuk format, seperti kode rekening, redaksi program/kegiatan, redaksi indikator kinerja program/kegiatan, dan redaksi kuantitas/unit pada laporan yang dikumpulkan oleh SKPD satu dengan yang lainnya berbeda-beda. 2) keterlambatan dalam proses penyampaian laporan, karena sulitnya akses ke beberapa SKPD tertentu yang jaraknya sangat jauh dari kota. 3) kesalahan input data karena hanya mengandalkan penyimpanan konvensional menggunakan folder atau excel yang bisa saja tercecer, sehingga terjadi perbedaan dan redudansi antara data laporan yang dibuat saat ini dengan data sebelumnya, serta. 4) tidak adanya kontrol monitoring progress kegiatan per triwulan yang efektif dan efisien sehingga seringkali sulit mengidentifikasi seberapa besar presentasi keberhasilan progress/posisi realisasi terhadap target akhir tahun anggaran.

Dengan melihat kebutuhan untuk menyelesaikan berbagai permasalahan diatas, maka perlunya diterapkan suatu sistem informasi pelaporan monitoring dan evaluasi (monev) yang akan memberikan kemudahan akses bagi masing-masing SKPD dalam mengisi dan mengelola data pelaporan RPJMD dan RKPD. Saat ini, pengembangan aplikasi dan sistem informasi telah diterapkan pada banyak kasus, seperti monitoring persediaan barang (Birtha et al., 2010) (Liza \& Yupinti, 2012), sarana prasarana Dinas Perhubungan (Wibawa \& Julianto, 2016), indikator realisasi dan kemajuan pekerjaan Dinas PU (Brianorman \& Waspodo, 2019), sentra UMKM (Wahyuniardi et al., 2016), monitoring kegiatan pengawas Dinas Pendidikan (Fitri Rahmawati et al., 2019), dan monitoring evaluasi pada Sekretariat Daerah (Fauzia \& Marini, 2018).

Beberapa penelitian tersebut menunjukkan bahwa sistem informasi berhasil mengatasi permasalahan pelaporan konvensional, format pelaporan menjadi terstandar dan terukur. serta kemudahan dalam pemantauan kegiatan. Namun, dari beberapa sistem informasi yang ada tersebut, terdapat beberapa kelemahan, diantaranya dalam penelitian Fauzia dan 
Marini (2018), aplikasi masih bersifat stand-alone yang tidak fleksibel, karena harus dinstal pada masing-masing komputer dan sangat tergantung pada OS tertentu. Kemudian dalam penelitian (Wibawa \& Julianto, 2016) dan (Wahyuniardi et al., 2016) yang mengembangkan sistem hanya menggunakan PHP native yaitu PHP tanpa framework MVC(ModelView-Controller), sehingga penempatan kode program cenderung tidak konsisten dan tidak terdokumentasi dengan baik, celah keamanan yang terbuka karena tidak adanya aturan yang jelas terkait struktur URL, enkripsi login, dan library yang digunakan, serta tidak cocok untuk proses bisnis yang luas.

Berdasarkan permasalahan tersebut, maka penelitian ini mengusulkan untuk mengembangkan Sistem Informasi Manajemen Pengendalian dan Evaluasi Pembangunan Daerah Kabupaten Tana Tidung yang dikenal dengan sebutan Simdalev. Simdalev ini akan dibangun dalam bahasa pemrograman web PHP berbasis CodeIgniter dan Harviacode.

CodeIgniter merupakan salah satu framework pemrograman PHP yang bersifat open source dan mengusung konsep MVC yang terdiri dari (Rasputri, 2011): 1) Model merupakan kode program (berupa OOP class) yang digunakan untuk memanipulasi relasi basis data. 2) View merupakan kode program yang digunakan sebagai template $\mathrm{html} / \mathrm{xml}$ untuk menampilkan data pada browser. 3) Controller merupakan kode program yang digunakan untuk mengontrol aliran logika aplikasi. Ketiga konsep MVC dalam CodeIgniter inilah yang akan memisahkan antara logika pemrograman dengan presentasi, sehingga seorang programmer bisa berkonsentrasi pada core-system, sedangkan webdesigner bisa berkonsentrasi pada tampilan (Irawan \& Sulistyowati, 2017). Berbagai fitur CodeIgniter, diantaranya library dan helper yang lengkap, adanya xss filtering dan session encryption untuk sekuritas yang handal, mengizinkan pengembang web menggunakan library atau helper yang tidak disediakan oleh CodeIgniter, mendukung banyak RDBMS, serta mendukung Clean URL dan SEO (Search Engine Optimazation) (EllisLab, 2019). Sedangkan Harviacode merupakan generator yang mempermudah dalam pembuatan fitur CRUD (Create, Read, Update, dan Delete) dalam suatu form, karena hanya dengan menekan tombol generate, maka sudah jadi form CRUD dengan MVC yang terhubung langsung dengan basis data, datatable, paginasi, pencarian, dan export ke excel/word. Pengembang hanya tinggal melengkapi fitur tampilan menu dengan CSS, login adminitrasi, relasi basis data, session untuk masing-masing level user, dan library tambahan untuk melengkapi fitur pada form yang akan dibangun (Tim Harviacode, 2016) (Akbar, 2016).
Diharapkan dengan menggunakan framework CodeIgniter dan generator CRUD Harviacode dalam pengembangan Simdalev KTT, maka akan menghasilkan aplikasi web monitoring dan evaluasi yang efektif dan akurat dengan performa yang dinamis, cepat dan resource yang ringan dalam menghimpun, menganalisis dan menyusun pelaporan hasil evaluasi dan monitoring realisasi kegiatan SKPD di lingkungan KTT, serta dapat mengawal kegiatan agar tetap on the track sesuai RKPD dan dapat dijadikan langkah deteksi dini apabila terdapat ketidaksesuaian antara pelaksanaan dengan perencanaan.

\section{METODOLOGI PENELITIAN}

Metode Waterfall atau biasa disebut SDLC (Software Development Life Cycle, Siklus Hidup Pengembangan Sistem) yang akan digunakan sebagai metode perancangan aplikasi Simdalev ini. Tahapan dalam metode ini terdiri dari analisis awal kebutuhan sistem, perancangan sistem, generate source-code sistem, pengujian sistem, serta pemeliharaan sistem (Sommerville, 2011).

\section{Analisis Awal Kebutuhan Sistem}

Agar sistem ini dibuat sesuai dengan kondisi riil, maka diperlukan adanya analisis awal kebutuhan dari para pengguna sistem tersebut. Dari analisis awal diperoleh data yaitu:

- Data pengguna sebanyak 26 SKPD dengan 1 SKPD yaitu Sekretariat Daerah memiliki 6 sub bidang dan perekapan seluruh data dilakukan oleh Bappeda Litbang KTT. Untuk itu, masing-masing SKPD akan dibuatkan akun disertai pembagian level pengguna yang sesuai dengan fungsinya masing-masing.

- Fokus Simdalev menghasilkan dokumen laporan RKPD. Beberapa komponen yang harus dikembangkan dalam Simdalev, yaitu basis data kode rekening untuk SKPD, kode rekening untuk program, kode rekening untuk kegiatan dengan indikator kinerja/program, target renstra hingga akhir tahun RPJMD, realisasi capaian kinerja SKPD hingga tahun lalu, target kinerja SKPD tahun berjalan, realisasi kinerja per triwulan, perbandingan nilai target dengan realisasi kinerja, hingga nilai capaian dan predikat kinerja yang muncul secara otomatis.

\section{Perancangan Sistem}

Hasil analisis kebutuhan awal, kemudian menjadi landasan untuk merancang sistem. Usulan use case diagram sistem yang akan dikembangkan dapat dilihat pada Gambar 1. Gambar 1 menunjukkan bahwa untuk dapat mengakses Simdalev, maka semua pengguna harus melakukan login terlebih dahulu. Jika berhasil login, maka operator dapat memanfaatkan fitur yang berbeda-beda dalam aplikasi ini berdasarkan level 
pengguna.

Tabel 1. Alat dan Bahan Pengembangan Sistem

\begin{tabular}{|l|l|}
\hline Alat Bantu & Kegunaan dan Fungsi \\
\hline UML & $\begin{array}{l}\text { Untuk visualisasi dan perancangan } \\
\text { use case diagram Simdalev }\end{array}$ \\
\hline Notepad++ & $\begin{array}{l}\text { Untuk membuat source code } \\
\text { Simdalev }\end{array}$ \\
\hline $\begin{array}{l}\text { Apache XAMPP } \\
7.3 .7\end{array}$ & $\begin{array}{l}\text { Untuk menjalankan source code } \\
\text { lingkungan web browser }\end{array}$ \\
\hline CodeIgniter & $\begin{array}{l}\text { Framework Mada dalam } \\
\text { pemrograman PHP yang akan } \\
\text { digunakan }\end{array}$ \\
\hline Harviacode & $\begin{array}{l}\text { Generator yang mendukung dalam } \\
\text { pembuatan form CRUD berbasis } \\
\text { framework CodeIgniter }\end{array}$ \\
\hline Ion Auth Library & $\begin{array}{l}\text { Library pada CodeIgniter yang } \\
\text { mendukung proses authentifikasi } \\
\text { Simdalev }\end{array}$ \\
\hline AdminLTE & $\begin{array}{l}\text { Template yang digunakan sebagai } \\
\text { antarmuka Simdalev }\end{array}$ \\
\hline
\end{tabular}

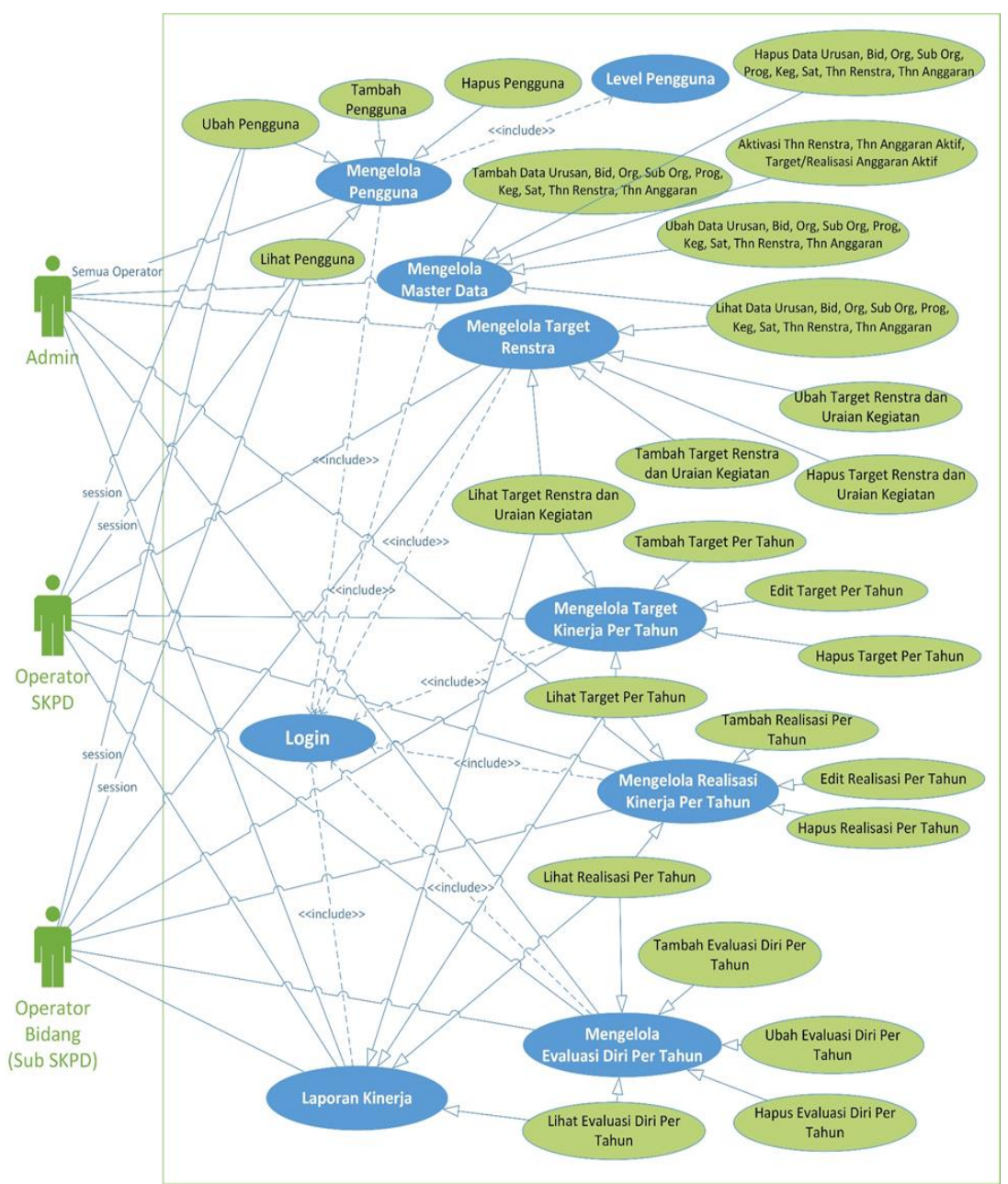

Gambar 1. Usulan Use Case Diagram Simdalev

Pembagian masing-masing level pengguna diantaranya: 1) Level admin yang memiliki hak akses seluruh SKPD, diantaranya data pengguna, master data (berisikan kode rekening dan nama rekening untuk data urusan, bidang, organisasi, sub organisasi, program, kegiatan, satuan, tahun renstra, dan tahun anggaran), data target renstra (berisikan program kerja, uraian kegiatan, nilai anggaran), data target kinerja per tahun (nilai target anggaran pada tahun berjalan), data realisasi kinerja per tahun (nilai realisasi anggaran pada tahun berjalan), data evaluasi diri (komentar kekurangan dan saran pada tahun berjalan), dan data laporan kinerja (menampilkan data target dan realisasi anggaran yang akan disesuaikan dengan format pelaporan RKPD). 2) Level organisasi yang memiliki hak akses satu SKPD dan beberapa sub bidang dibawahnya, diantaranya: lihat dan ubah data pengguna (akunnya sendiri), data target renstra, data target kinerja, data realisasi kinerja per tahun, data evaluasi diri, dan data laporan kinerja. 2) Level sub organisasi yang fungsinya sama dengan level organisasi, akan tetapi hanya memiliki hak akses kesatu sub bidang saja.

\section{Generate source-code sistem}

Simdalev diimplementasikan ke dalam bahasa pemrograman web PHP berbasis Codeigniter dan Harviacode, dengan dukungan alat bantu tambahan dalam mendesain template, form, dan proses bisnis sistem. Alat dan bahan yang digunakan dapat dilihat pada Tabel 1 .

\section{Pengujian Sistem}

Pengujian dilakukan guna mengetahui seberapa benar sistem dapat berjalan sesuai dengan analisis awal kebutuhan sistem dan perancangan sistem. Proses pengujian menggunakan tiga jenis pengujian, yaitu (Pressman, 2010):

- $\quad$ Pengujian black-box untuk memvalidasi apakah hasil pengujian fungsionalitas sistem sudah sesuai dengan rancangan use case yang diusulkan.

- Pengujian kompabilitas untuk memastikan apakah sistem dapat digunakan pada berbagai macam browser. Pengujian diukur menggunakan aplikasi sortSite (Fitri Rahmawati et al., 2019).

- $\quad$ Pengujian usabilitas untuk mengevaluasi sejauh mana sistem mudah digunakan dan dapat dipahami pengguna. Pengujian ini diukur menggunakan lembar System Usability Scale (SUS) berskala likert yang berisi 10 pertanyaan, dengan rentang jawaban dari nilai 1 menyatakan sangat tidak setuju sampai dengan 5 sangat setuju (Fitri Rahmawati et al., 2019). Pengujian dilakukan terhadap 33 responden (1 admin Bappeda, 26 SKPD, dan 6 sub bidang 
SKPD).

\section{Implementasi dan Pemeliharaan sistem}

Setelah pengujian Simdalev, selanjutnya akan diberikan support secara menyeluruh terhadap proses implementasi dan pemeliharaan aplikasi Simdalev, mulai dari instalasi program, training ke pengguna hingga troubleshoot atau penanganan jika terdapat kesalahan program atau kendala yang dialami oleh pengguna.

\section{HASIL DAN PEMBAHASAN}

Simdalev yang telah dibuat dapat diakses pada situs simdalev.tanatidungkab.go.id/. Tampilan awal akses berupa menu login seperti yang ditunjukkan pada Gambar 2. Untuk masuk ke Simdalev harus memasukkan email dan password operator yang sudah terdata. Jika berhasil masuk, maka tampilan akan diarahkan ke menu dashboard. Menu dashboard yang digunakan untuk melihat perbandingan nilai anggaran target dengan realisasi secara visual grafik.

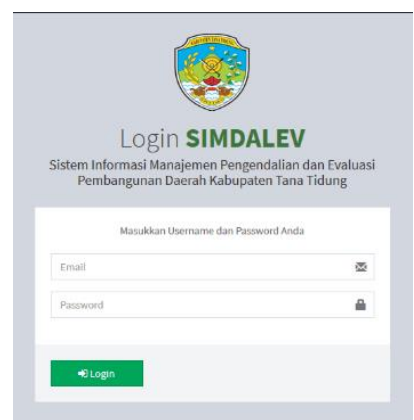

Gambar 2. Menu Login Simdalev

Terdapat tampilan yang berbeda untuk menu dashboard Admin dengan Organisasi/Sub Organisasi. Pada operator dengan hak akses Admin, tampilan visual anggaran dapat difilter berdasarkan akumulasi semua SKPD atau satu per satu, serta filter yang menampilkan visual anggaran semua SKPD berdasarkan akumulasi tahun renstra maupun per tahun anggaran (dapat dilihat pada Gambar 3). Pada operator dengan hak akses Organisasi/Sub Organisasi, tampilan visual anggaran dapat difilter berdasarkan akumulasi tahun renstra maupun per tahun anggaran untuk satu SKPD saja (dapat dilihat pada Gambar 4). Selain itu, fitur menu juga dibedakan antara Admin dengan Organisasi/Sub Organisasi sesuai dengan diagram use case. Fitur menu untuk Admin, diantaranya: 1) Dashboard, 2) Pengaturan, 3) Master Data, dan 4) Kinerja. Sedangkan fitur menu yang aktif untuk Organisasi/Sub Organisasi hanya menu Kinerja.

Gambar 3. Dahsboard Admin

Gambar 4. Dashboard Organisasi/Sub Organisasi

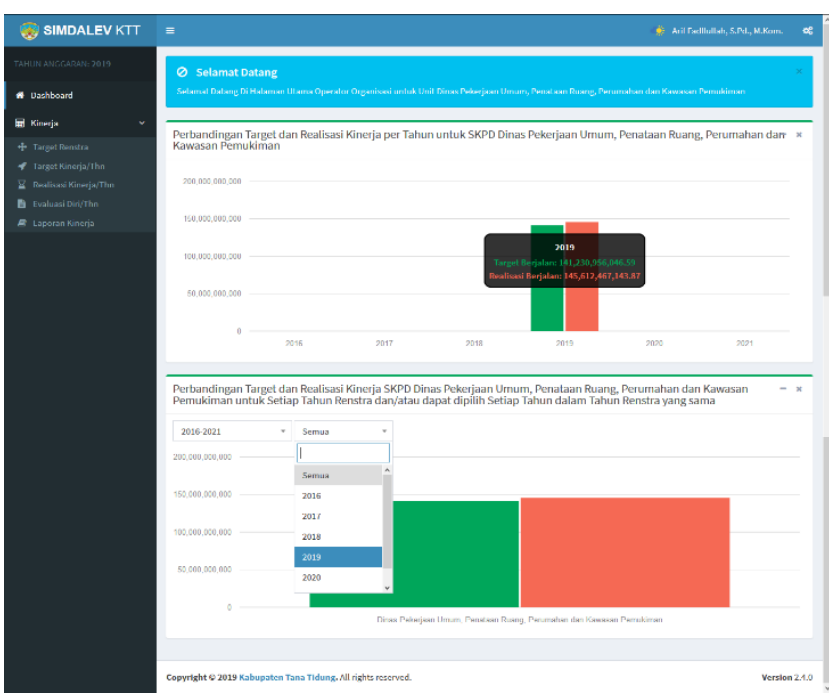

Terdapat dua menu khusus Admin, yaitu menu Pengaturan dan menu Master Data. Di menu Pengaturan, terdapat sub menu Kelola Pengguna yang berfungsi untuk menambahkan operator baru, mengubah atau menghapus operator. Tampilan sub menu Kelola Pengguna dapat dilihat pada Gambar 5.

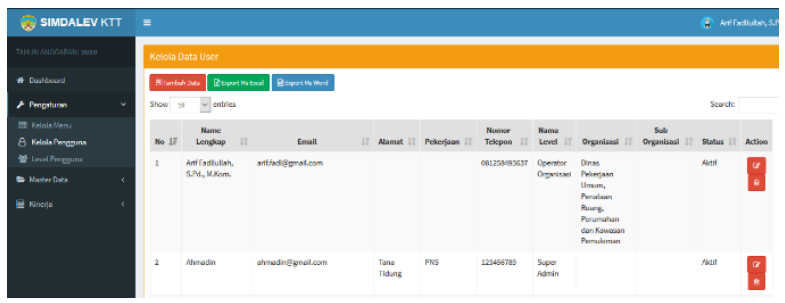

Gambar 5. Sub Menu Kelola Pengguna

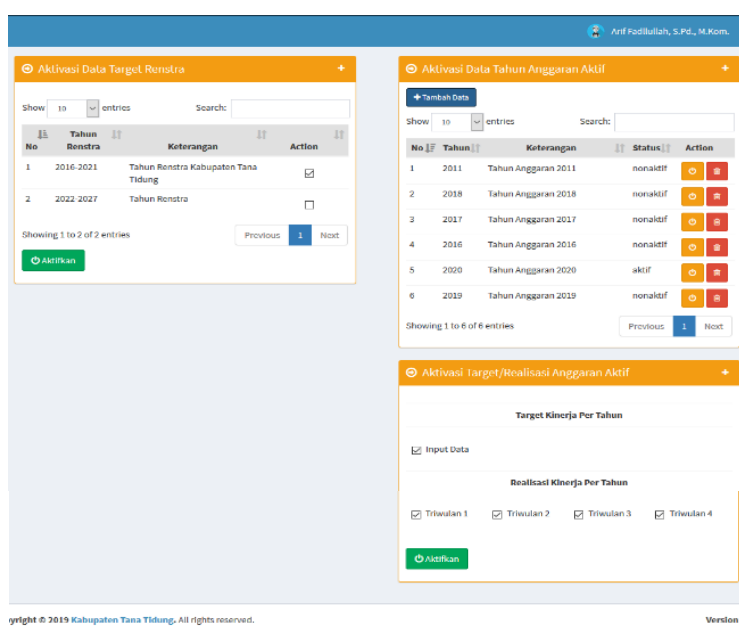

Jika ingin menambahkan data operator pengguna, cukup klik tombol tambah, maka akan diarahkan ke form input Data User seperti yang ditunjukkan pada Gambar 6. Pilih organisasi dan pilih sub organisasi akan muncul, jika level user yang dipilih adalah organisasi/sub organisasi. Data pilih organisasi dan sub organisasi akan muncul dari basis data yang telah diisi di master data.

1. Menu Khusus Admin 


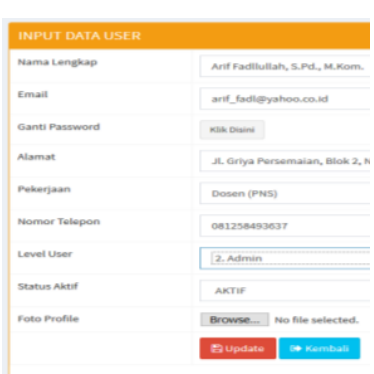

(a)

Gambar 6. Form Input Data User saat memilih level user Admin (a) dan saat memilih Operator Organisasi (b)

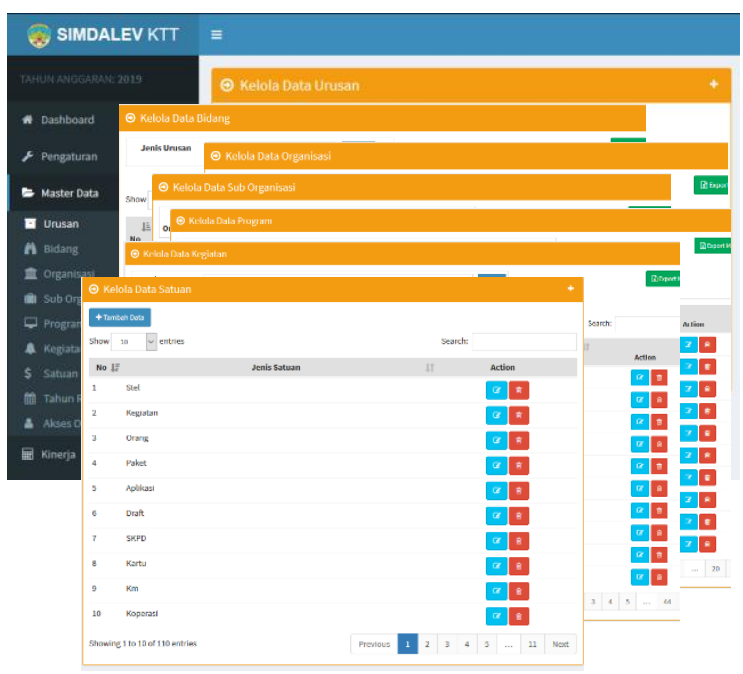

Gambar 7. Menu Master Data

Gambar 7 menunjukkan menu Master Data memiliki beberapa sub menu yang hanya dapat diakses khusus Admin, diantaranya: Sub Menu Urusan, Bidang, Organisasi, Sub Organisasi, Program, Kegiatan, Satuan, Tahun Renstra, dan Akses Operator. Semua menu akan menampilkan data dalam bentuk tabel dengan paginasi. Data ini wajib diisi agar dapat mengisi menu Kinerja. Khusus untuk sub menu Akses Operator seperti yang ditunjukkan pada Gambar 8, digunakan untuk mengaktifkan form untuk pengisian data target renstra berdasarkan tahun renstra dan mengaktifkan data tahun anggaran berjalan. Selain itu pada sub menu ini terdapat isian checklist pada kotak dialog Aktivasi Target/Realisasi Anggaran Aktif yang digunakan untuk mengaktifkan atau mengunci form di sub menu Target Kinerja/Tahun dan Realisasi Kinerja/Tahun pada menu Kinerja. Dengan sub menu ini, Admin dapat mengatur kapan waktunya form pengisian nilai anggaran untuk target maupun realisasi akan diisi maupun dikunci.

Gambar 8. Sub Menu Akses Operator

\section{Menu untuk Admin dan Organisasi/Sub Organisasi}

Terdapat satu menu yang dapat diakses oleh level pengguna Admin dan Organisasi/Sub Organisasi yaitu menu Kinerja. Menu Kinerja ini memiliki sub menu yang terdiri dari: Target Renstra, Target Kinerja/Thn, Realisasi Kinerja/Thn, Evaluasi Diri/Thn, dan Laporan Kinerja.

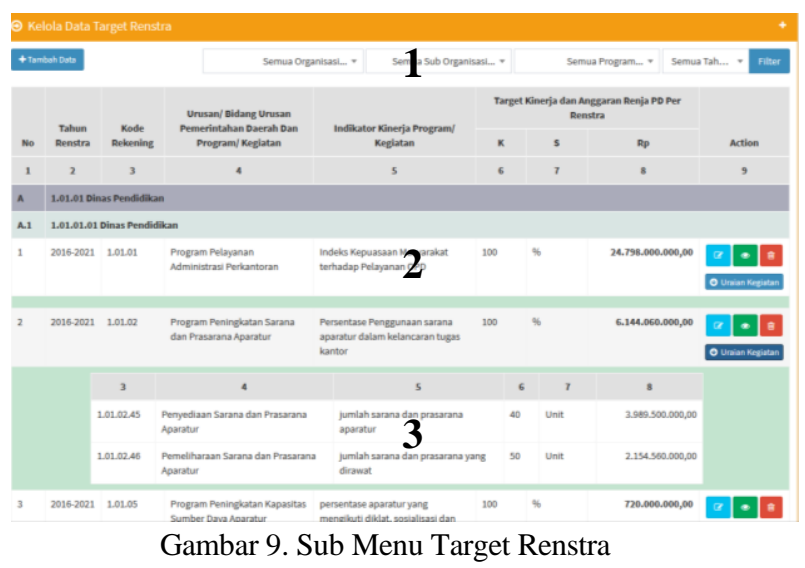

Gambar 9 menunjukkan tampilan dari sub menu Target Renstra. Menu ini akan menampilkan data instrumen target renstra, seperti tahun renstra, kode rekening dan keterangannya untuk urusan, bidang, program, kegiatan, dan indikator kinerja program/kegiatan, serta persentase dan nilai anggaran yang dikeluarkan untuk target renstra. Jika sub menu diakses menggunakan operator Admin, maka data target renstra untuk semua SKPD yang dimunculkan, tetapi data ini dapat dimunculkan sebagian dengan melakukan filter menggunakan fungsi filter seperti yang ditunjukkan pada Gambar 9 bagian 1. Sedangkan jika sub menu diakses menggunakan operator Organisasi/Sub Organisasi, maka data target satu SKPD/sub bidang SKPD yang dikelola operator itu saja yang akan ditampilkan. Jika ingin menambahkan data target renstra cukup klik tombol Tambah Data pada sub menu Target Renstra (lihat Gambar 9), maka akan muncul form seperti yang ditunjukkan pada Gambar 10. Pada form ini diisi nama sub organisasi dan jenis program (data ini diambil otomatis dari menu Master Data), indikator kinerja, jangka waktu renstra, target dan satuan target, kemudian klik simpan. Jika disimpan, maka data akan muncul di sub menu Target Renstra seperti yang ditunjukkan pada Gambar 9 bagian 2 . Untuk menambahkan detail beberapa kegiatan untuk satu program. Caranya cukup klik tombol hijau pada deretan tombol per item data di sub menu Target Renstra, maka akan muncul sub menu Uraian Kegiatan seperti yang ditunjukkan pada Gambar 11. Data ini diisi dengan mengklik tombol Tambah Kegiatan sehingga muncul form Input Data Uraian Kegiatan seperti yang ditunjukkan pada Gambar 12. 


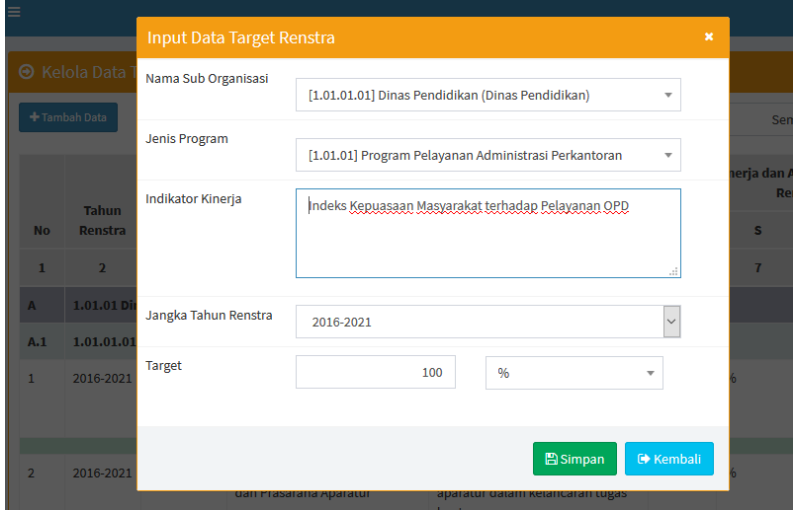

Gambar 10. Form Input Data Target Renstra

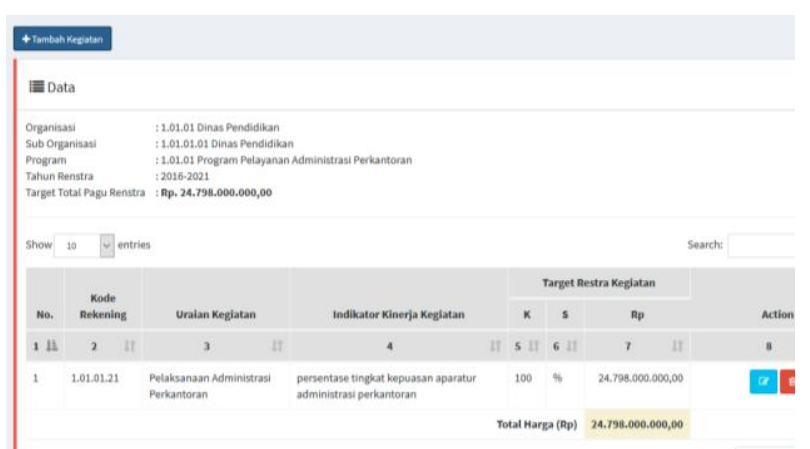

Gambar 11. Data Uraian Kegiatan/Program dengan Pengisian Nominal Target Renstra Kegiatan

Pada form ini diisi jenis kegiatan (data ini diambil otomatis dari menu Master Data), indikator kinerja, kuantitas, satuan, jumlah, kemudian klik simpan. Data uraian yang masuk akan disimpan dan diakumulasi total anggarannya secara otomatis sebagai nilai anggaran dari satu program target renstra.

Berikutnya sub menu Target Kinerja/Thn berfungsi untuk mengisi persentase dan nilai anggaran untuk target kinerja selama 1 tahun, dimana untuk redaksi uraian program dan detail kegiatan secara otomatis diambil dari data yang telah diisi dari sub menu Target Renstra. Cara pengisian sama seperti sub menu Target Renstra, tetapi yang bisa diisi hanya persentase dan nilai anggaran saja.

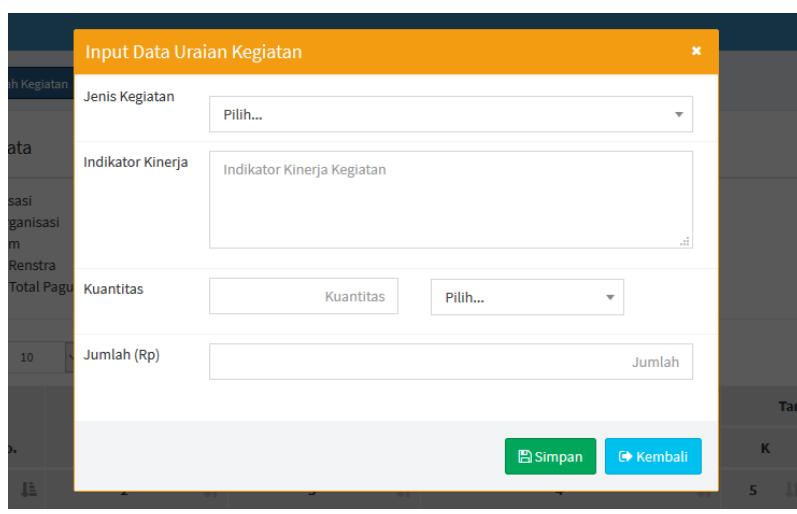

Gambar 12. Form Input Data Uraian Kegiatan

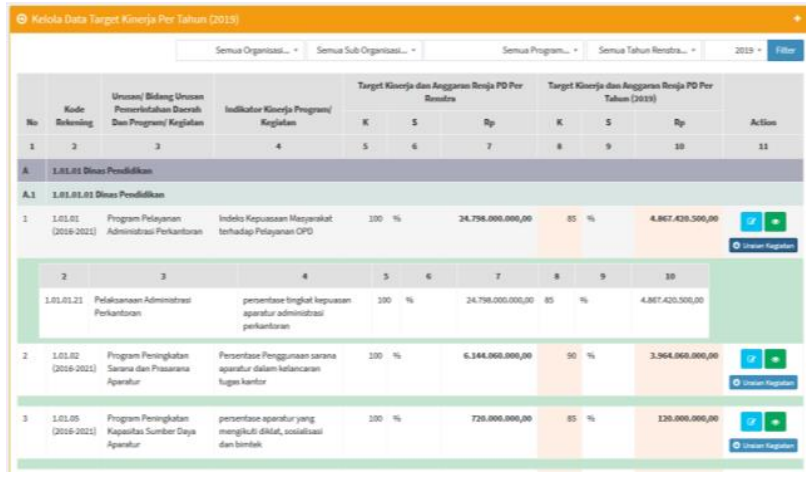

Gambar 13. Sub Menu Target Kinerja/Tahun

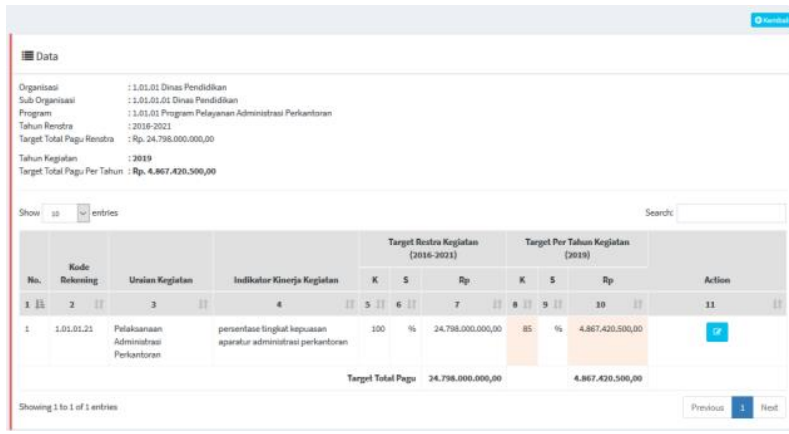

Gambar 14. Data Uraian Kegiatan/Program dengan Tambahan Pengisian Nominal Target/Tahun Kegiatan

Gambar 13 menunjukkan tampilan sub menu Target Kinerja/Tahun dan Gambar 14 menunjukkan tampilan data Uraian Kegiatan Per Tahun. Pada bagian yang ditandai warna kuning pada tabel dari kedua menu tersebut merupakan data yang harus diisi sebagai target tahunan. Gambar 15 merupakan contoh form input Data Uraian Kegiatan Per Tahun dengan jenis kegiatan dan indikator kegiatan diambilkan datanya secara otomatis dari data Uraian Kegiatan. Pada form ini yang diisi hanya target kuantitas dan jumlah anggaran selama setahun.

Berikutnya Gambar 16 menunjukkan tampilan sub menu Realiasi Kinerja/Thn yang berfungsi untuk mengisi nilai anggaran untuk realisasi kinerja selama 1 tahun, dimana untuk redaksi uraian program dan detail kegiatan secara otomatis diambil dari data yang telah diisi dari sub menu Target Kinerja/Thn. Cara pengisian sama seperti sub menu Target Kinerja/Thn, tetapi yang bisa diisi hanya persentase dan nilai anggaran saja.

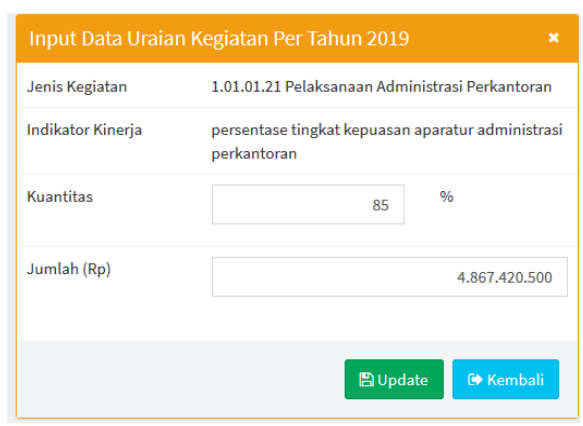


Gambar 15. Form Input Data Target Anggaran dan Kuantitas Kegiatan/Tahun

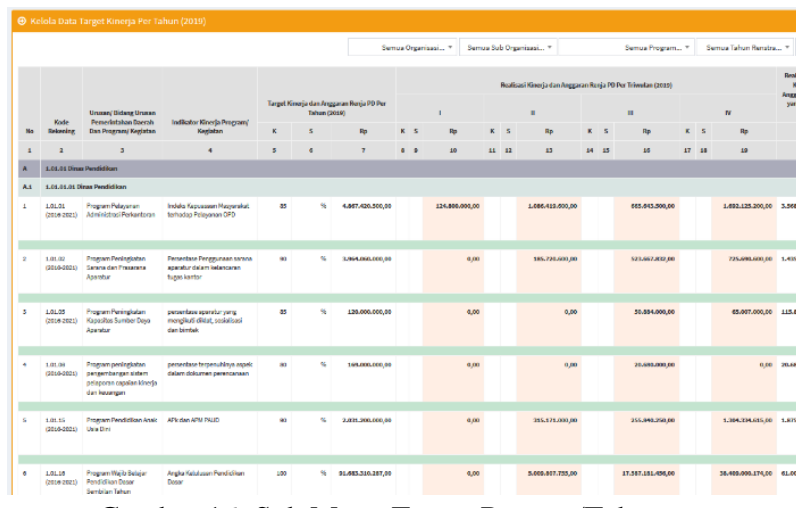

Gambar 16. Sub Menu Target Renstra/Tahun

Kolom yang ditandai warna kuning pada Gambar 16 merupakan data akumulasi nilai anggaran realisasi uraian kegiatan dalam satu program per triwulan I, II, III, dan IV. Untuk mengisi akumulasi tersebut, perlu mengisi anggaran realisasi per uraian kegiatan per triwulan. Gambar 17 menunjukkan daftar uraian kegiatan dalam satu program. Sedangkan Gambar 18 menunjukkan form data Uraian Realisasi Kegiatan Per Tahun yang diisi nilai anggarannya per triwulan. Kolom triwulan ini bisa dikunci oleh Admin sewaktuwaktu dengan menghilangkan centang kolom triwulan di kotak dialog Aktivasi Target/Realisasi Anggaran Aktif pada sub menu Akses Operator yang seperti yang ditunjukkan pada Gambar 8.

Jika semua data terpenuhi, maka proses download data dapat dilakukan sesuai dengan format RKPD. Gambar 19 menunjukkan hasil laporan dalam bentuk word yang di download dari Simdalev. Sedangkan Gambar 20 menunjukkan bagaimana hasil laporan secara otomatis mampu memberikan penilaian terhadap capaian kinerja yang telah dilaksanakan berupa nilai ST (Sangat Tinggi), T (Tinggi), S (Sedang), R (Rendah), SR (Sangat Rendah).

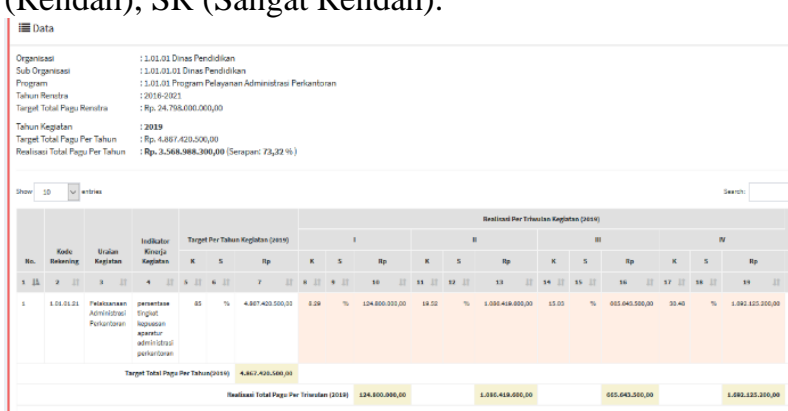

Gambar 17. Uraian Kegiatan/Program dengan Tambahan Pengisian Nominal Realisasi/Tahun Kegiatan

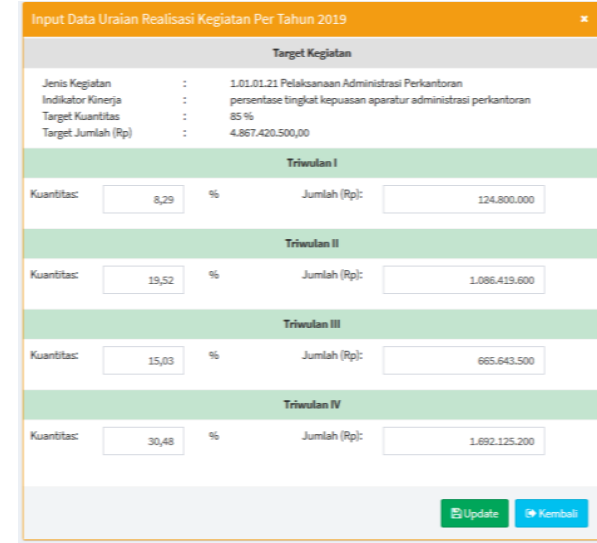

Gambar 18. Form Input Data Realisasi Anggaran Kegiatan/Triwulan

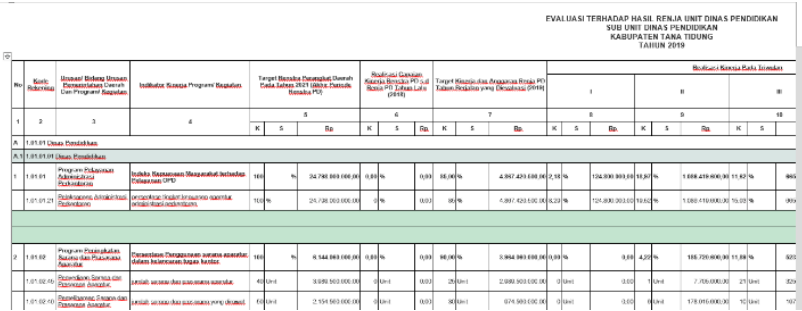

Gambar 19. Laporan Kinerja dalam Bentuk Word

\begin{tabular}{|c|c|c|c|c|c|c|c|c|}
\hline 62,33 & $3.568 .988 .300,00$ & & 73,32 & & $3.568 .988 .300,00$ & & 14,39 & \\
\hline 73.32 & $3.568 .988 .300,00$ & 86,28 & 73,32 & 73,32 & $3.568 .988 .300,00$ & 73,32 & 14,38 & Dinas Rerodidikan \\
\hline & Canaian Kineria & 86,26 & 73,32 & & & 73,32 & 14,39 & \\
\hline & Exedikat Kineria & $\mathrm{T}$ & $\mathrm{s}$ & & & s & SR & \\
\hline
\end{tabular}

Gambar 20. Nilai Capaian dan Predikat Kinerja

\section{Pengujian Simdalev}

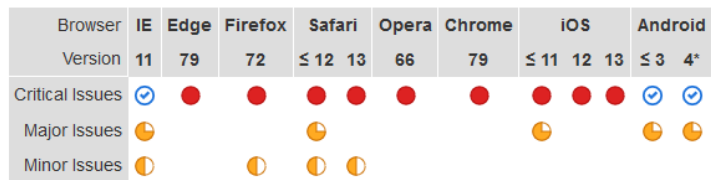

* Most Android devices from 4.4 onwards use Chrome as the default browser, older versions use the

\section{Priority Description and URL}

\section{Priority 1}

1 issues on 1 pages

$\checkmark \quad$ Browsers display multiple security warnings for password fields that don't use HTTPS

Gambar 21. Hasil Pengujian Compabilitas dengan Critical Issues

\section{Priority 2}

3 issues on 4 pages

$\triangleright$ CSS hex colors with alpha values like \#RGBA or \#RRGGBBAA are not supported by all browsers.

$\Delta$ The css filter. property is not supported by some browsers

$\triangle$ The css transiorm: property is not supported by some older browsers.

\section{Priority 3}

5 issues on 2 pages

$\triangle$ DilectX fitters are not supported by IE 10 or later

D The box-shadow: css propery is not supported by older browsers

$\triangle$ (1) The orphans: css property is not supported by some browsers.

D (1) The page-break-after. CSS property values avoid, left and right are not supported by Firefox.

$\triangleright$ The widows: css property is not implemented by some browsers. 
Gambar 22. Hasil Pengujian Compabilitas dengan Major dan Minor Issues

Tabel 2. Hasil Pengujian Black-box

\begin{tabular}{|c|l|c|c|c|}
\hline \multirow{2}{*}{ No. } & \multicolumn{1}{|c|}{ Kasus Uji } & \multicolumn{2}{|c|}{ Hak Akses } & \multirow{2}{*}{ Status } \\
\cline { 3 - 4 } & & Admin & $\begin{array}{c}\text { Org/ } \\
\text { Sub Org }\end{array}$ & Valid \\
\hline 1. & Melakukan Login & $\sqrt{ }$ & $\sqrt{ }$ & Valid \\
\hline 2. & $\begin{array}{l}\text { Menampilkan } \\
\text { Grafik pada } \\
\text { Dashboard }\end{array}$ & $\sqrt{ }$ & $\sqrt{ }$ & Valid \\
\hline 3. & $\begin{array}{l}\text { Mengelola } \\
\text { Pengguna }\end{array}$ & $\sqrt{ }$ & - & Valid \\
\hline 4. & $\begin{array}{l}\text { Mengelola Master } \\
\text { Data }\end{array}$ & $\sqrt{ }$ & - & Valid \\
\hline 5. & $\begin{array}{l}\text { Mengelola Akses } \\
\text { Operator }\end{array}$ & $\sqrt{ }$ & - & Valid \\
\hline 6. & $\begin{array}{l}\text { Mengelola Target } \\
\text { Renstra }\end{array}$ & $\sqrt{ }$ & $\sqrt{ }$ & Valid \\
\hline 7. & $\begin{array}{l}\text { Mengelola Target } \\
\text { Kinerja Per Tahun }\end{array}$ & $\sqrt{ }$ & $\sqrt{ }$ & $\begin{array}{l}\text { Mengelola } \\
\text { Realisasi Kinerja } \\
\text { Per Tahun }\end{array}$ \\
\hline 8. & $\begin{array}{l}\text { Mengelola Evaluasi } \\
\text { Diri Per Tahun }\end{array}$ & $\sqrt{ }$ & $\sqrt{ }$ & Valid \\
\hline 10. & $\begin{array}{l}\text { Mengelola Laporan } \\
\text { Kinerja }\end{array}$ & $\sqrt{ }$ & $\sqrt{ }$ & Tidak \\
\hline
\end{tabular}

Tabel 3. Hasil Pengujian Usabilitas

\begin{tabular}{|c|c|c|c|}
\hline No & Responden & Skor & $\underset{(\mathbf{x} 2)}{\mathrm{SU}}$ \\
\hline 1 & Administrator & 38 & 76 \\
\hline 2 & Op. Dinas Pendidikan & 42 & 84 \\
\hline 3 & Op. Dinas Kesehatan & 43 & 86 \\
\hline 4 & $\begin{array}{l}\text { Op. Dinas Pekerjaan Umum, } \\
\text { Penataan Ruang, Perumahan dan } \\
\text { Kawasan Pemukiman }\end{array}$ & 38 & 76 \\
\hline 5 & $\begin{array}{l}\text { Op. Satuan Polisi Pamong Praja } \\
\text { dan Pemadam Kebakaran }\end{array}$ & 39 & 78 \\
\hline 6 & $\begin{array}{l}\text { Op. Badan Penanggulangan } \\
\text { Bencana Daerah }\end{array}$ & 40 & 80 \\
\hline 7 & $\begin{array}{l}\text { Op. Dinas Sosial, Pemberdayaan } \\
\text { Masyarakat dan Desa }\end{array}$ & 36 & 72 \\
\hline 8 & $\begin{array}{l}\text { Op. Dinas Lingkungan Hidup } \\
\text { dan Perhubungan }\end{array}$ & 38 & 76 \\
\hline 9 & $\begin{array}{l}\text { Op. Dinas Kependudukan dan } \\
\text { Pencacatan Sipil }\end{array}$ & 40 & 80 \\
\hline 10 & $\begin{array}{l}\text { Op. Dinas Komunikasi dan } \\
\text { Informatika }\end{array}$ & 42 & 84 \\
\hline 11 & $\begin{array}{l}\text { Op. Dinas Penanaman Modal, } \\
\text { Tenaga Kerja, Transmigrasi dan } \\
\text { Pelayanan Terpadu Satu Pintu }\end{array}$ & 43 & 86 \\
\hline 12 & $\begin{array}{l}\text { Op. Dinas Pariwisata, Pemuda } \\
\text { dan Olahraga }\end{array}$ & 40 & 80 \\
\hline 13 & $\begin{array}{l}\text { Op. Dinas Pertanian, Pangan dan } \\
\text { Perikanan }\end{array}$ & 38 & 76 \\
\hline 14 & $\begin{array}{l}\text { Op. Dinas Perindustrian, } \\
\text { Perdagangan, Koperasi, UKM }\end{array}$ & 42 & 84 \\
\hline 15 & $\begin{array}{l}\text { Op. Dewan Perwakilan Rakyat } \\
\text { Daerah }\end{array}$ & 42 & 84 \\
\hline 16 & Op. Sekretariat Daerah & 44 & 88 \\
\hline 17 & Op. Bagian Umum & 39 & 78 \\
\hline 18 & Op. Bagian Tata Pemerintahan & 38 & 76 \\
\hline
\end{tabular}

\begin{tabular}{|c|l|c|c|}
\hline No & \multicolumn{1}{|c|}{ Responden } & Skor & $\begin{array}{c}\text { SU } \\
\text { (x 2) }\end{array}$ \\
\hline 19 & $\begin{array}{l}\text { Op. Bagian Kesejahteraan } \\
\text { Rakyat }\end{array}$ & 42 & 84 \\
\hline 20 & Op. Bagian Hukum & 42 & 84 \\
\hline 21 & $\begin{array}{l}\text { Op. Bagian Organisasi dan } \\
\text { Humas }\end{array}$ & 40 & 80 \\
\hline 22 & $\begin{array}{l}\text { Op. Bagian Perekonomian dan } \\
\text { Pembangunan }\end{array}$ & 42 & 84 \\
\hline 23 & Op. Sekretariat DPRD & 40 & 80 \\
\hline 24 & Op. Kecamatan Sesayap & 40 & 80 \\
\hline 25 & Op. Kecamatan Sesayap Hilir & 42 & 84 \\
\hline 26 & Op. Kecamatan Tana Lia & 42 & 84 \\
\hline 27 & Op. Kecamatan Betayau & 40 & 80 \\
\hline 28 & Op. Kecamatan Muruk Rian & 43 & 86 \\
\hline 29 & $\begin{array}{l}\text { Op. Kesatuan Bangsa dan } \\
\text { Politik }\end{array}$ & 37 & 74 \\
\hline 30 & Op. Inspektorat Kabupaten & 41 & 82 \\
\hline 31 & $\begin{array}{l}\text { Op. Badan Perencanaan } \\
\text { Pembangunan Daerah dan } \\
\text { Litbang }\end{array}$ & 42 & 84 \\
\hline 32 & $\begin{array}{l}\text { Op. Badan Pengelolaan } \\
\text { Keuangan dan Aset Daerah }\end{array}$ & 40 & 80 \\
\hline 33 & $\begin{array}{l}\text { Op. Badan Kepegawaian dan } \\
\text { Pengembangan SDM }\end{array}$ & 38 & 76 \\
\cline { 2 - 4 } & \begin{tabular}{l} 
JUMLAH SU \\
\cline { 2 - 4 }
\end{tabular} & $\mathbf{2 6 6 6}$ \\
\hline \multirow{2}{*}{ SKOR USABILITAS (JUM SU/33) } & $\mathbf{8 0 , 7 9}$ \\
\hline
\end{tabular}

Gambar 21 menunjukkan hasil pengujian kompabilitas menggunakan aplikasi SortSite. Hasil pengujian menunjukkan bahwa secara umum Simdalev dapat diakses pada seluruh browser. Hanya saja terdapat critical issues pada beberapa browser yang menampilkan beberapa peringatan keamanan untuk form login, karena tidak menggunakan HTTPS. Selain itu, Gambar 22 menunjukkan major dan minor issues terkait fitur css property pada Simdalev yang tidak support pada beberapa browser, sehingga mempengaruhi tampilan Simdalev yang sedikit berbeda pada masing-masing browser. Akan tetapi hal ini tidak mengganggu performa Simdalev saat digunakan.

Tabel 2 menunjukkan hasil pengujian black-box yang valid untuk sebagian besar proses bisnis dalam menu aplikasi dan telah sesuai dengan rancangan use case. Hanya saja pada bagian mengelola laporan kinerja, tampilan export word dan pdf pada menu Laporan Kinerja yang masih over margin untuk kasus data yang jumlah string kata sangat panjang dan detail, sehingga perlu dilakukan kostumisasi margin dan ukuran kertas yang lebih besar.

Selain itu, Tabel 3 menunjukkan hasil pengujian usabilitas sistem terhadap responden, yang mana nilai usabilitas mencapai skor 80,79, sehingga aplikasi Simdalev ini sudah dikatakan berada pada Grade B (Baik) dan mudah digunakan oleh operator. Hanya saja berdasarkan pengamatan dan pengujian usabilitas, terdapat beberapa kekurangan aplikasi 
yang perlu diperbaiki. Menu yang ditampilkan untuk hak akses level admin menjadi lambat ketika semua SKPD telah melakukan pengisian data, karena data tersebut ditampilkan seluruhnya di tabel form pada menu. Untuk itu, perlu perbaikan pada tabel form dengan penambahan paginasi (penomoran) yang meload setiap 10 data, tidak seluruhnya. Fitur dashboard yang bisa dilengkapi lebih baik dengan tidak hanya menampilkan perbandingan nilai anggaran target kinerja dan realisasi kinerja saja, akan tetapi mampu memunculkan log proses bisnis dan notif menu mana yang belum diisi oleh pengguna.

\section{KESIMPULAN DAN SARAN}

Pengujian black-box menunjukkan hasil yang valid untuk sebagian besar proses bisnis dalam menu aplikasi dan telah sesuai dengan rancangan use case. Hasil pengujian kompatibilitas aplikasi Simdalev yang menunjukkan bahwa Simdalev dapat berjalan baik di berbagai macam browser. Dan hasil pengujian usabilitas didapatkan nilai 80,79 yang berada pada grade B yang menyatakan antarmuka aplikasi Simdalev baik dan dapat digunakan oleh pengguna dengan mudah.

\section{REFERENSI}

Akbar, N. (2016). Racode Generator tools for development. https://belajarphp.net/racode-generator-tools-fordevelopment-2/

Birtha, A., Soemantri, M., \& Abdian, F. (2010). Aplikasi Sistem Informasi Persediaan Barang pada Perusahaan Export Hasil Laut Berbasis Web. Transmisi, 12(1).

Brianorman, Y., \& Waspodo. (2019). Sistem Informasi Monitoring dan Evaluasi dengan Menggunakan Kurva S sebagai Indikator Realisasi dan Kemajuan Pekerjaan. JEPIN (Jurnal Edukasi Dan Penelitian Informatika), 5(3), 344-351.

EllisLab. (2019). CodeIgniter Features. https://codeigniter.com/user_guide/overview/feature s.html

Fauzia, E., \& Marini. (2018). Sistem Informasi Laporan Monitoring Evaluasi (MONEV) Pada Sekretariat Daerah Kabupaten Bangka Tengah. In Konferensi Nasional Sistem Informasi (pp. 8-9).

Fitri Rahmawati, A., Tolle, H., \& Indah Rokhmawati, R. (2019). Pengembangan Sistem Informasi Monitoring Dan Evaluasi Hasil Kegiatan Pengawas Berbasis Web (Studi Kasus : Dinas Pendidikan Kota Malang) (Vol. 3, Issue 3, pp. 2452-2458).

Humas KTT. (2016). Sejarah Tana Tidung. http://tanatidungkab.go.id/sejarah-tana-tidung.html

Irawan, R., \& Sulistyowati. (2017). Implementasi Framework CodeIgniter untuk Pengembangan Website pada Dinas Perkebunan Provinsi Kalimantan Tengah. Jurnal Saintekom, 7(1), 67-80.
Liza, Y., \& Yupinti. (2012). Sistem Informasi persediaan barang pada PT.Surya Nusa Bhaktindo Bengkulu. Media Infotama, 8(1), 90-117.

Maghfiroh, N. A. (2017). Efektivitas Sistem Informasi Pelaporan Monitoring Dan Evaluasi (E-Controlling) Pada Bagian Evaluasi Pembangunan Sekretariat Daerah Kota Bontang. In Jurnal Paradigma (JP) (Vol. 5, Issue 1, pp. 34-44). http://ejournals.unmul.ac.id/index.php/JParadigma/article/vi ew/426/383

Mardiasmo. (2012). Otonomi dan Manajemen Keuangan Daerah: Serial Otonomi Daerah. Andi Offset.

Monev Untuk Perencanaan yang Lebih Baik. (2019). http://www.dlhk.jogjaprov.go.id/monev-untukperencanaan-yang-lebih-baik

Pressman, R. S. (2010). Software Engineering: A Practitioner's Approach. McGraw-Hill.

Rasputri, I. A. (2011). Perancangan Sistem Informasi Pengolahan Data Pemesanan Dan Produksi Furniture Pada CV. Annisa Prima Karya. Universitas Komputer Indonesia.

Sommerville, I. (2011). Software Engineering Ninth Edition. Addison-Wesley.

Tim Harviacode. (2016). Update Harviacode CRUD Generator https://harviacode.com/2016/11/26/updateharviacode-crud-generator-1-4/

Tim Penyusun Evaluasi RKPD. (2019). Rencana Kerja Pemerintah Daerah Kabupaten Tana Tidung Tahun 2019. http://tanatidungkab.go.id/pustaka/467_RKPD KTT 2019.pdf

Wahyuniardi, R., Afrianti, L. H., Nurjaman, S., \& Gusdya, W. (2016). Pembangunan Sistem Informasi Berbasis Web untuk Monitoring dan Evaluasi Sentra Industri Kecil dan Menengah di Jawa Barat. Jurnal Ilmiah Teknik Industri, 4(1), 9-19.

Wibawa, J. C., \& Julianto, F. (2016). Rancang Bangun Sistem Informasi Monitoring Dan Evaluasi Pembangunan Sarana Dan Prasarana Pada Dinas Perhubungan Kota Surabaya. In Jsika (Vol. 2, Issue 33, pp. 173-185). 